\title{
Population and distribution mapping of dispersed Asiatic wild ass in human dominated landscape using remote sensing \& GIS.
}

\author{
Divyarajsinh Parmar ${ }^{1 *}$, Chintan Pathak ${ }^{2}$, Aditya Vora ${ }^{3}$ \\ ${ }^{1 *}$ CU Shah University, Faculty of Sciences (Physics), Wadhwan, Gujarat, India \\ ${ }^{2}$ Gujarat Institute of Disaster Management, Gandhinagar, Gujarat, India \\ ${ }^{3}$ Gujarat University, Dept. of Physics, Gujarat, India \\ *Corresponding Author: divyarajsinhji@gmail.com, Tel.: +91-9409043060
}

Available online at: www.isroset.org

Received 30/Dec/2017, Revised 15/Jan/2018, Accepted 29/Jan/2018, Online 28/Feb/2018

\begin{abstract}
Presence of wild animal in the farmlands (human dominated landscape) is observed at various places due to various reasons. Asiatic Wild Ass (Equus hemionus khur) is aboriginal inhabitant of Little Rann of Kutchchh (LRK), Gujarat state, India. But today (Jan'2018), it is well seen as far as $80-100 \mathrm{~km}$ away from nearest fringe of its actual habitat. In this research paper, we have mapped population and distribution through the data of 10 years using Remote sensing and GIS in context to Asiatic wild ass in a selected patch of farmlands near Surendranagar town, Gujarat state, India. Geo-spacial techniques are much useful in analysis and mapping of wildlife in human dominated areas. ArcGIS and QGIS software were used for map preparation. Such maps are helpful to understand adaptation strategies of wild animals in human dominated areas. Study of movement maps of animal help us to understand the reasons of dispersal. It helps conservationist to mitigate the dispersal of wild animal in future.
\end{abstract}

Keywords—QGIS, Asiatic Wild Ass, Equus hemionus khur, Remote sensing, Dispersion, Man-Animal conflict, Little Rann of Kutchchh, LRK

\section{INTRODUCTION}

Man-Animal conflict is most common problem in and around biodiversly rich areas eg. Little Run of Kutchchh, Gir WLS\&NP, Velavadar NP etc. due to many reasons viz. species conservation, population increase, crop depredation in the human dominated landscape near Wildlife Sanctuary or National Park in developed /developing countries [1]. Due to various causes, wild animals are well seen in the human dominated landscapes especially farmlands or cattle grazing areas just on the periphery of a wildlife sanctuary or a park. Asiatic wild Ass (inhabitant of LRK) are observed very well dispersed (up to $60-100 \mathrm{Km}$ from the nearest fringe of LRK) from their habitat [2]. Using developed tools like Remote Sensing and GIS, along with it precise systematic ground proofing, detail of animals' distribution can be mapped [3]. Frequency of presence in certain areas helps to identify the resourceful areas. In this paper, remote sensing has been used to locate the animals in the landscape, information regarding topography and vegetation of the area. On the other hand, GIS has been used to map distribution of animal, crop varieties, vegetation and water sources in the entire landscape through the selected time span.

Study contains,
1. Population variation of Wild ass in the landscape

2. Population distribution in the entire landscape over the years 2007-2017

3. Analysis of the landscape based on food and water resources for the animal

This paper is organized in five sections viz. Introduction contains review s of previous work and hypothesis of the study. Study area contains information about the landscape where the study has been conducted. Objectives contains possible outcome looking for. Research methodology introduces to the methods opted. Analysis, Result and Discussion section contains information about outputs obtained at the end of study. Conclusion informs about success proportions and limitations.

\section{STUdY AREA}

Gujarat State is located on the western edge of India, it stretches across $20^{\circ} 01^{\prime} \mathrm{N}$ and $24^{\circ} 07^{\prime} \mathrm{N}$ latitudes and $68^{\circ}$ $10^{\prime} \mathrm{E}$ and $74^{\circ} 28^{\prime} \mathrm{E}$ longitudes. With total geographic coverage of approx. 1,96,000 $\mathrm{km}^{2}$ [4]. District Surendranagar is located exactly in the center of the State with the capital of 
Surendranagr Town with population around 1,77,851 (Census'2011) [5]. The weather is seasonal with annual rainfall appx $87.35 \mathrm{~mm}$ [6]. North-east end of the district is attached with arid mud / salt flat spreading across 4953.7 $\mathrm{Km} 2$ [7]. Gujarat, known as Little Rann of Kutchchh. Its fringe touches to Banaskantha, Surendranagar and Kutchcch districts [8]. Asiatic wild ass is permanent inhabitant of this landscape, but their large congregation is seen only at the shunt of Surendranagar. The town is approx. $45 \mathrm{~km}$ away from the nearest edge of LRK (Little Rann of Kutchch) in South- West direction [9].

Herds of Wild Asses are visible in the farmlands around the town up to $15 \mathrm{~km}$. At $12.2 \mathrm{Km}$ away from Western edge of the town, a cluster of 203 farmlands owned by local farmers of Danawada village are located covering the area of appx
600 hectors. Geographic location of the area is $22044^{\prime} \mathrm{N}$ to $22045^{\prime} \mathrm{N}$ latitudes and $71031^{\prime} \mathrm{E}$ to $71033.5^{\prime} \mathrm{E}$ longitudes. Topologically, surface has inclination of $1.14 \mathrm{o}$ towards north-west. There are two seasonal ponds: one with of water capacity $16000000 \mathrm{ltr}$ at westward to the area and the other with the water capacity of 13200000 ltr south-west of the area. A single lane road crosses the area in to two sections heading towards the village Danawada, Digsar and Pandavara villages. Most of the farmers cultivate caster (ricinus communis) and juwar (sorghum), ones in the year. There are few uncultivated patches covered with prosopis (prosopis julifloralittle). The underneath surface is mostly dry in the year except in monsoon. Fig.1 shows the entire landscape (LRK) as Study Area and specific 5 different Zones

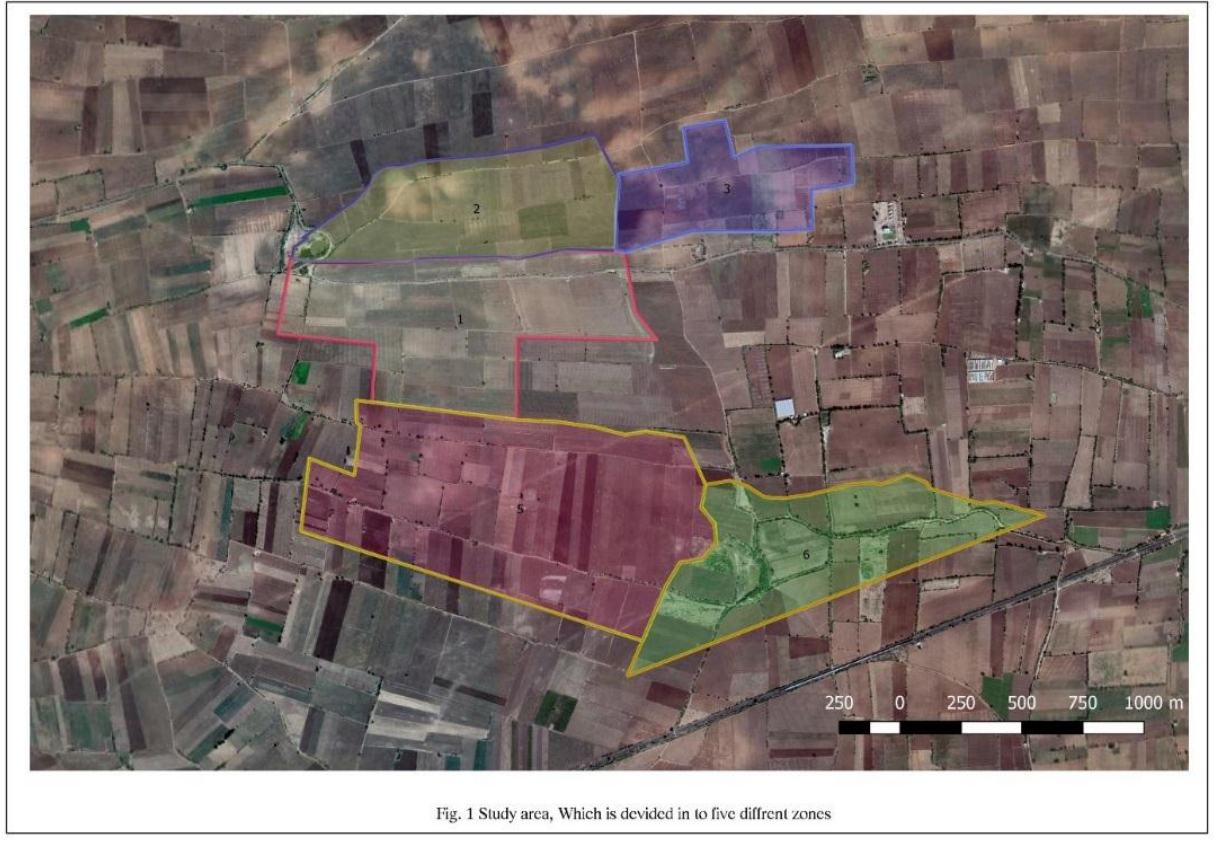

Figure 1 Study area (Source-BHUVAN Portal)

\section{RESEARCH METHODOLOGY}

Software like QGIS, ArcGIS is used for demonstrating population of wild asses present in the area across last 10 years.

1. GIS database about population of wild ass in the region(landscape) has been created with regular field visits with minimum gap of 1 day/visit and maximum gap of 16 days/visit. GPS observations were recorded with Garmin GPS etrex10 device with the accuracy of around $30 \mathrm{ft}$.
2. Remote sensing data related to Topological information of the area was obtained from Bhuvan portal and GoogleMaps ${ }^{\mathrm{TM}}$, data related to presence of farmer in the farm has been obtained from observation during field visits and with routine interrogative conversations with them.

Water and food resources were identified through field observation with animals' visit for the water and food purposes with 8.2 /10 visit's accuracy. 


\section{QGIS ANALYSIS}

Database related to presents of wild ass in the landscape made with GPS points with field visits along with different attributes such as month-year of observation, gender, agegroup, activity, latitude, longitude, Id signs, Photo ID etc.

Fig.2 was the analytic result of their (whose population) population estimate and distribution of the Month January' 2017.
As shown in Figure.3 (below), the selected landscape contains four main water resources for wild ass (indicated with ' $\mathrm{W}$ ' in the map). Out of them two are ponds which remains partially filled with monsoon water. While other two are the dripping water points from the joint of water supply pipes running from Narmada canals at Surendranagar to the village Digsar, for drinking purpose. Grazing areas are mostly uncultivated farms or farmlands with seasonal cultivation. which contains different types of weeds as well. There are such patches in zone no. 2, 3 and 5. While zone 1 and 6 often cultivated with Sesame and Jowar.

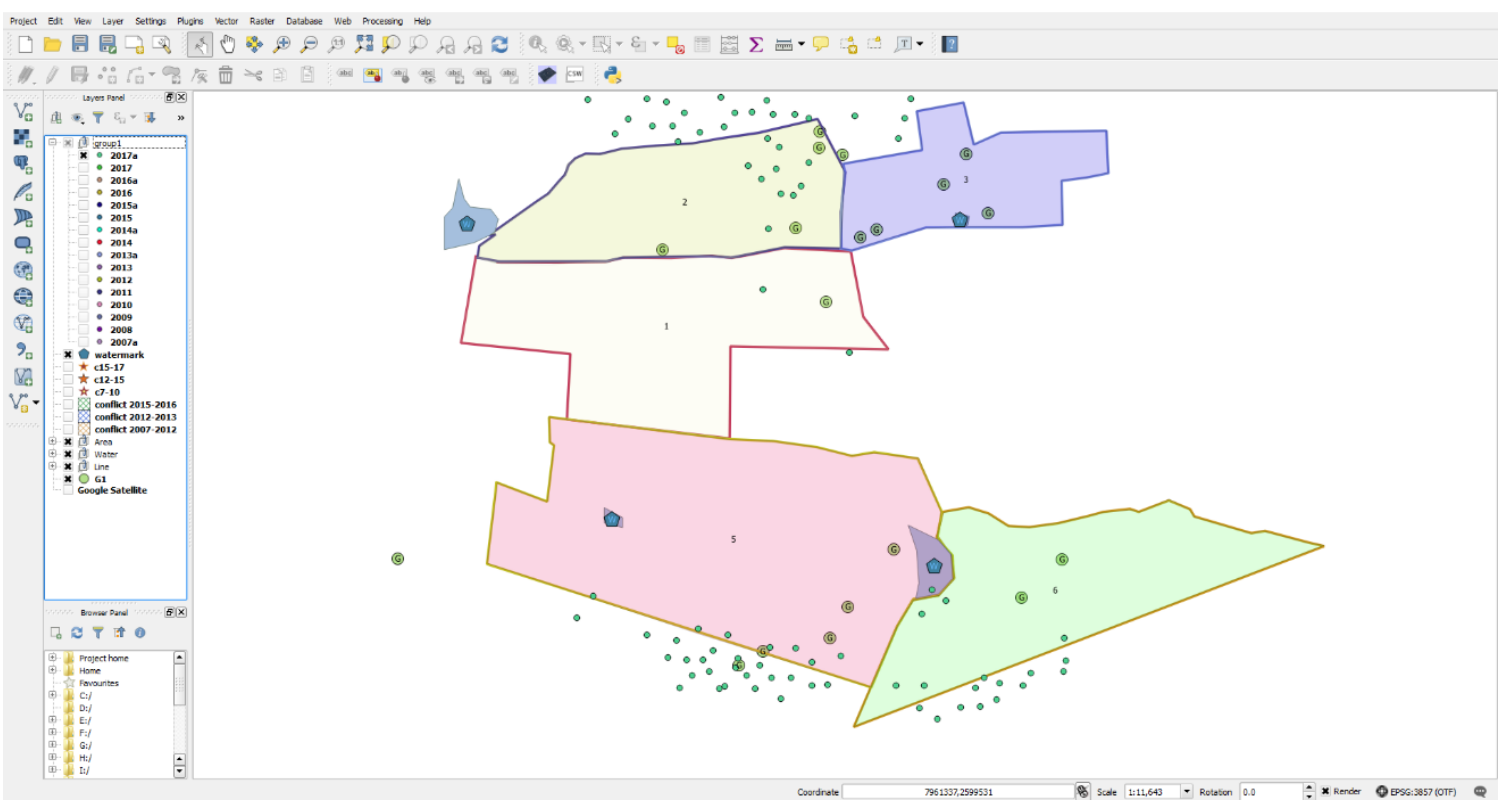

Figure.2 GIS analysis in QGIS for individuals present in the landscape in Jan'2017

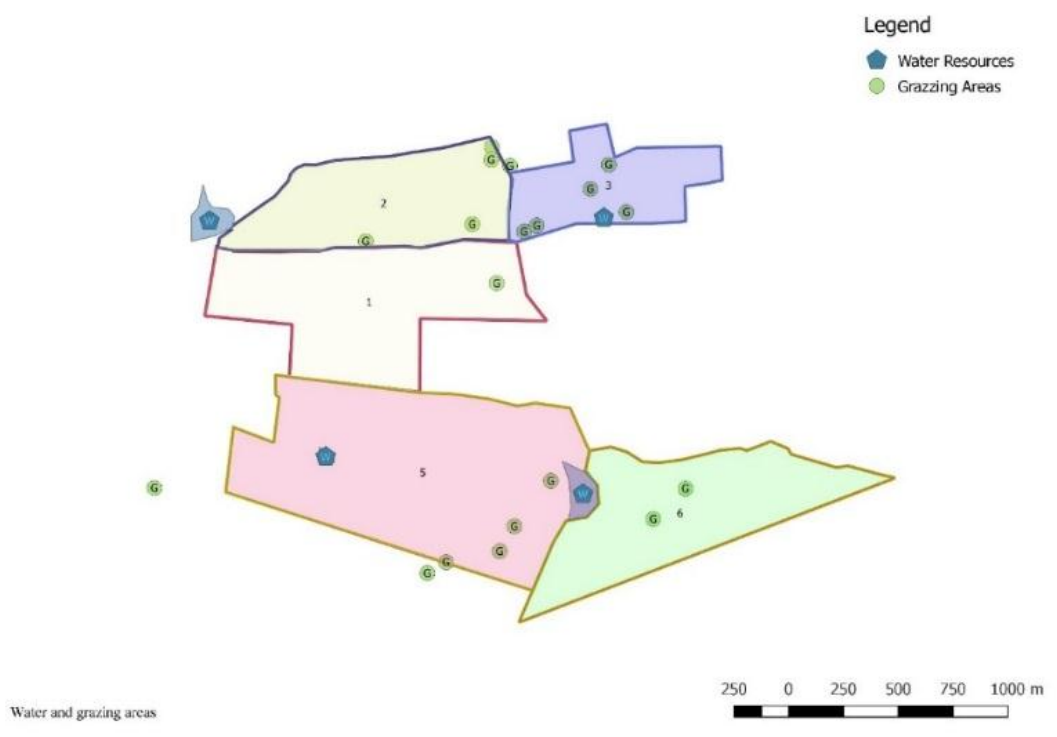

Figure.3 Water resources of and Grazing resources 


\section{RESULT AND DiscuSSION}

Using GIS and remote sensing as a tool, the population variation of wild ass obtained is shown in Table I and Fig. 4(a). Zone wise population has increased compared to the previous years in all the zones except in zone 1 and zone 3 after 2012 and 2015 respectively.

The population of wild ass has decreased in zone. 1 and zone 3 after said years. During field visits increased farming activity due to availability to water through canal was observed after the year 2012 in zone 1 and construction work at residential scheme under taken in zone 3 around 2012. It would be the cause of dispersion of the animals from the said zones.

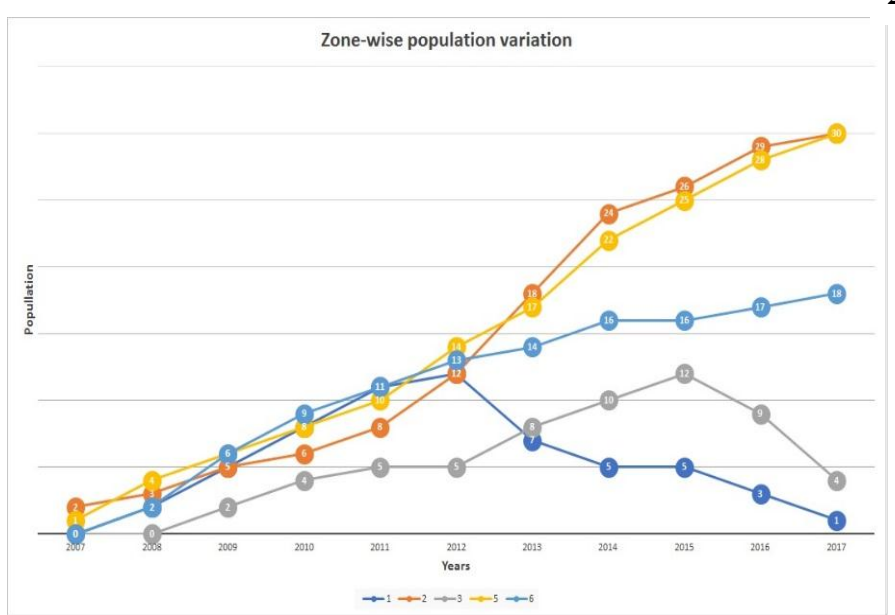

Figure.4(a) population variation chart in the selected zones.

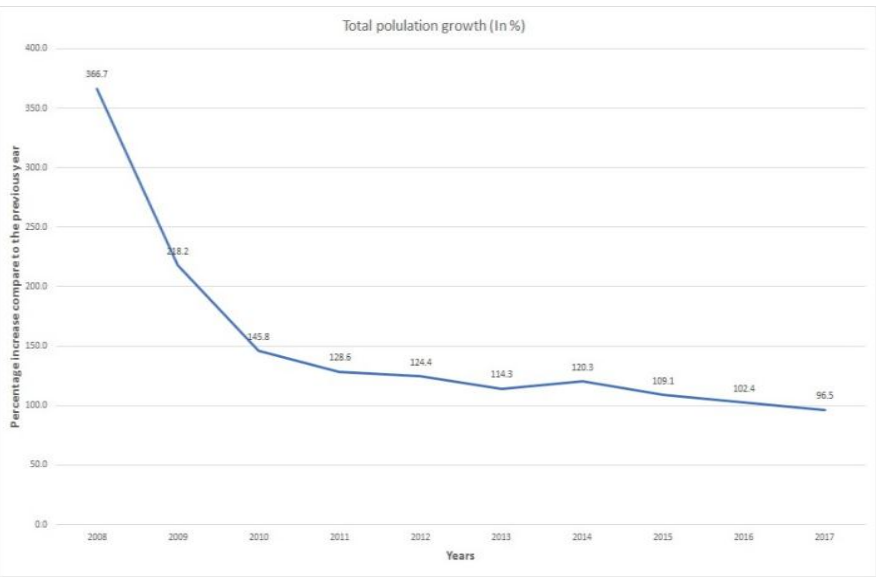

Figure.4(b) Percentage growth in population compared to the previous year.
Table. 1 Population variation in the selected zones

\begin{tabular}{|c|c|c|c|c|c|c|}
\hline & Zone:1 & Zone:2 & Zone:3 & Zone:5 & Zone:6 & Total \\
\hline 2007 & 0 & 2 & 0 & 1 & 0 & 3 \\
\hline 2008 & 2 & 3 & 0 & 4 & 2 & 11 \\
\hline 2009 & 5 & 5 & 2 & 6 & 6 & 24 \\
\hline 2010 & 8 & 6 & 4 & 8 & 9 & 35 \\
\hline 2011 & 11 & 8 & 5 & 10 & 11 & 45 \\
\hline 2012 & 12 & 12 & 5 & 14 & 13 & 56 \\
\hline 2013 & 7 & 18 & 8 & 17 & 14 & 64 \\
\hline 2014 & 5 & 24 & 10 & 22 & 16 & 77 \\
\hline 2015 & 5 & 26 & 12 & 25 & 16 & 84 \\
\hline 2016 & 3 & 29 & 9 & 28 & 17 & 86 \\
\hline 2017 & 1 & 30 & 4 & 30 & 18 & 83 \\
\hline
\end{tabular}
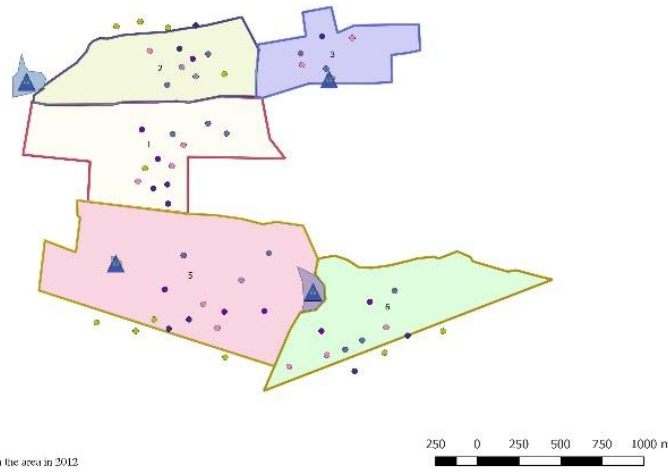

Figure 5(a). Population distribution in 2012

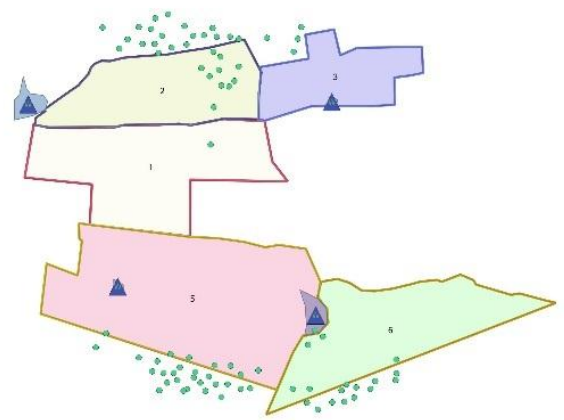

Figure.4(b) Percentage growth in population compared to the previous year. 


\section{Conclusions}

This research paper shows extensive use of remote sensing data and GIS in the population estimation and mapping of dispersed wild animal in human dominated landscape. This tool is helpful for such analysis, but it also demands high resolution satellite imagery for landscape analysis. Such analysis would provide further details about use of resources and causes of dispersion.

\section{ACKNOWLEDGMENT}

I am thankful to my guide Dr. Aditya Vora, Professor, Dept. of Physics, Gujarat University for his constant support and encouragement in preparation of this paper. We also acknowledge Mr Mehul Lakhani for his constant support in the field work and data collection.

Mr. Vidyut Vikas, BCRLIP, Wild Ass Sanctuary Dhrangadhra helped us in understanding the behavioural part of wild asses. I thank my wife, Mandavi and my son, Vyom for support and understand my unavailability while preparation of this paper.

\section{REFERENCES}

[1] Prater 1980; Rajpurohit \& Mohnot 1988; Sukumar, 1994

[2] Rufford technical report. 2009-2010, "Understanding conflicts and conservation of Indian wild ass around Little Rann of Kachchh, Gujarat, India".

[3] T Thapa, "Habitat Suitability evaluation for leopard using Remote sensing and GIS in and around Chitwan National Park", Nepal, 2011.

[4] Directorate of Economics and statistics, 1987.

[5] http://www.census2011.co.in

[6] H N Tiwari, "District Ground Water Brochure (Surendranagar District)", CGWB, 2014, pp.7

[7] K Ishnava, "Ecologically important and life supporting plants of little Rann of Kachchh", Journal of Ecology and the Natural Environment Vol. 3(2), February 2011, pp. 34

[8] Management plan, Wild Ass Sanctuary, Gujarat. India, 2015

[9] N V Shah, "Ecology of wild ass in Little Rann of Kuchchh", 1993

\section{AUTHORS PROFILE}

Mr. D V Parmar pursed M.Sc in Physical science from Sardar Patel University, Vallabh Vidyanagar in 1998. He is currently working as higher secondary in Aided school, Surendranagar since 1998. He is working with dispersed wild ass as a part of his doctorate. $\mathrm{He}$ is a keen naturalist and wildlife photographer. He has won several national international awards for wildlife photography. He has published 8 research papers in known international journals and conferences. He has 18 years teaching experience and 7 years research experience. 